\title{
Roles for host and tumor angiotensin II type 1 receptor in tumor growth and tumor-associated angiogenesis
}

\author{
Nozomi Imai ${ }^{1}$, Tatsuo Hashimoto ${ }^{1}$, Minoru Kihara ${ }^{1}$, Shin-ichiro Yoshida ${ }^{1}$, Ichiro Kawana ${ }^{1}$, Takuya Yazawa ${ }^{2}$, \\ Hitoshi Kitamura² and Satoshi Umemura'
}

Angiotensin II (AII) is a multifunctional bioactive peptide, and host renin-angiotensin system (RAS) is closely associated with tumor growth. Recent reports have described that All is a proangiogenic growth factor, and that Angiotensin II type 1 (AT1) receptor antagonists reduce tumor growth and tumor-associated angiogenesis. In this paper, we investigated the participation of AT1 receptor-signaling in cancer progression using murine Lewis lung carcinoma (LLC) cells, which express AT1 receptor, and AT1a receptor gene-deficient (AT1a-/-) mice. When LLC cells were implanted subcutaneously into wild-type (WT) mice, developed tumors showed intensive angiogenesis with an induction of vascular endothelial growth factor (VEGF) a. Compared with WT mice, tumor growth and tumor-associated angiogenesis was reduced in AT1a-/- mice with reduced expression of VEGFa. In AT1a-/- mice, administration of the AT1 receptor antagonist, TCV116, showed further reductions of tumor growth, tumor-associated angiogenesis, and VEGFa expression. In vitro study, the expression of VEGFa mRNA and the production of VEGFa protein in LLC cells were significantly increased by All, which were cancelled by AT1 receptor antagonist, CV-11974. Although the expression of other angiogenic factors, such as angiopoietin-1, angiopoietin-2, epidermal growth factor, and VEGF receptor $2 \mathrm{mRNA}$, was also investigated in tumor tissues, the expression of VEGFa was most correlated with tumor size among those other angiogenic factors. VEGFa induction by AT1 receptor-signaling in both host and tumor tissues is one of key regulators of tumor growth and tumor-associated angiogenesis. In conclusion, tumor tissue RAS as well as host tissue RAS were found to have an important role in tumor growth. AT1 receptor-signaling blockade may be a novel and effective target in the treatment of cancer.

Laboratory Investigation (2007) 87, 189-198. doi:10.1038/labinvest.3700504; published online 18 December 2006

KEYWORDS: angiogenesis; angiotensin II; AT1 receptor; tumor growth; VEGF

The renin-angiotensin system (RAS) plays important roles in the regulation of cardiovascular homeostasis and blood pressure. ${ }^{1}$ Many pathophysiological activities of angiotensin II (AII) are known to be mediated by the seven transmembrane receptors. Two major subtypes of AII receptors, namely AT1 receptor and AT2 receptor, have been identified, with the former having receptor subtypes, ATla and ATlb. ${ }^{2}$ Most of AII functions in the cardiovascular system are mediated through the AT1 receptor, and in rodents they are mediated through the AT1a receptor. ${ }^{3-6}$ Recently, many reports have suggested that AII is involved in other functions, such as apoptosis, vascular remodeling, and inflammation. ${ }^{7-9}$ As regards vascular remodeling, several studies have shown that AII promotes proliferation, migration, and growth factor synthesis in several types of vascular cells, including smooth muscle cells and pericytes. ${ }^{10-13}$ Other studies have also investigated the angiogenic effects of exogenous AII in vivo angiogenesis models. ${ }^{14-17}$ Furthermore, recent studies have revealed local expression of several components of the RAS in various cancer cells and tissues. ${ }^{18}$ A large-scale clinical trial for hypertension demonstrated that inhibitors of angiotensin-converting enzyme (ACE) reduced mortality rates not only of those due to cardiovascular diseases but also those due to malignant tumors. ${ }^{19}$ Although angiogenesis induced by ACE inhibitors has been reported, ${ }^{20,21} \mathrm{ACE}$ inhibitors have also been shown to inhibit tumor-associated angiogenesis in many previous studies. ${ }^{22-24}$ Recently, some reports using AT1 receptor antagonist and ATla receptor

\footnotetext{
'Department of Medical Science and Cardiorenal Medicine, Yokohama City University Graduate School of Medicine and School of Medicine, Yokohama, Kanagawa, Japan and ${ }^{2}$ Department of Cellular Pathobiology, Yokohama City University Graduate School of Medicine and School of Medicine, Yokohama, Kanagawa, Japan Correspondence: Dr T Hashimoto, MD, Department of Medical Science and Cardiorenal Medicine, Yokohama City University Graduate School of Medicine and School of Medicine, Fukuura 3-9, Kanazawa-ku, Yokohama, Kanagawa 236-0004, Japan. E-mail: tatsuo_h@med.yokohama-cu.ac.jp

Received 21 July 2006; revised 12 October 2006; accepted 17 October 2006; published online 18 December 2006
} 
gene-deficient (ATla-/-) mice have shown that the blocking of AT1a receptor-signaling inhibited growth of the following tumor cells: melanoma, ${ }^{25}$ lung, ${ }^{26}$ prostate, ${ }^{27}$ renal cell carcinoma, ${ }^{28}$ and pancreas. ${ }^{29}$ These studies suggested that AII induced tumor-associated angiogenesis by producing vascular endothelial growth factor (VEGF) a via AT1 receptor in host-derived stroma. However, the precise mechanisms about the contribution of AT1 receptor in tumor cells remain to be determined.

The aim of the present study was to clarify the mechanisms of AT1 receptor signaling to facilitate tumor growth and tumor-associated angiogenesis with special focus on the interaction between host-derived stroma and tumor cells. The results reported here may provide a novel and effective strategy to treat malignant tumors.

\section{MATERIALS AND METHODS Agents and Cell Culture}

An AT1 receptor antagonist, $( \pm)$ 1-(cyclohexyl-oxycarbonyloxy) ethyl 2-ethoxy-1-\{[2'-(1H-tetrazol-5-yl) biphenyl-4-yl]methyl $\}$ 1H-benzimidazole-7-carboxylate(TCV-116, CV11974) $)^{30}$ was a kind gift from Takeda Chemical Industries (Osaka, Japan). CV11974 is the active metabolite of TCV116 and used for in vitro experiments. AII was purchased from Sigma (St Louis, MO, USA).

Murine Lewis lung carcinoma (LLC) cells ${ }^{26,31}$ were provided by Riken Cell Bank (RCB No. 0558). Vascular smooth muscle cells (VSMC) from the thoracic aorta of 4-week-old male Wistar rats were prepared by the explant method. ${ }^{32}$ And human embryonic kidney (HEK) 293 cells were provided by ATCC (CRL-1573). These cells were cultured in Dulbecco's modified Eagle's medium (DMEM) supplemented with 10\% fetal bovine serum (FBS), penicillin $(100 \mathrm{U} / \mathrm{ml})$, and streptomycin $(100 \mathrm{U} / \mathrm{ml})$ (all obtained from Invitrogen $(\mathrm{ON}$, Canada)) at $37^{\circ} \mathrm{C}$ in a humidified atmosphere of $95 \%$ air and $5 \% \mathrm{CO}_{2}$.

\section{Animals}

Male C57BL/6J mice (WT mice, 8- to 10-week-old) were obtained from Charles River Japan, (Yokohama, Japan). Male AT1a-/ - mice (C57BL/6J background) were developed as reported previously. ${ }^{33}$ ATla $-/-$ mice $(n=32)$ and their WT counterparts $(n=33)$ were housed at a controlled humidity of $60 \pm 5 \%$ and a temperature of $25 \pm 1{ }^{\circ} \mathrm{C}$, with a 12-h light/ dark cycle. All animal experiments were performed in accordance with the guidelines for animal experiments set by the Animal Experiment Committee of Yokohama City University School of Medicine.

\section{siRNA Preparation}

Synthetic RNAs were purchased from Invitrogen (Stealth Invitrogen). The sequence of our prepared mouse angiotensinogen siRNA was $5^{\prime}$-UGU UGU UCA GAU UUG CCU CCG CAC C-3'; 3'-A CAA CAA GUC UAA ACG GAG GCG UGG-5'. Scramble oligo control siRNA duplex was also purchased from Stealth Invitrogen, and was used as controls. The siRNAs and Atelocollagen (Koken Co., Ltd, Tokyo, Japan) complexes were prepared as described by Minakuchi et al. ${ }^{34}$ Atellocollagen was used for siRNA stabilization and prolonged release of siRNA. An equal volume of Atelocollagen (in phosphate buffered saline (PBS) at $\mathrm{pH}$ 7.4) and siRNA solution was combined and mixed by rotation at $4^{\circ} \mathrm{C}$ for $20 \mathrm{~min}$. The complex was kept at $4^{\circ} \mathrm{C}$ for $16 \mathrm{~h}$ before use. Final concentration of Atelocollagen was $0.5 \%$.

\section{Tumor Implantation Model: Effects of Angiotensinogen siRNA and TCV-116}

LLC cells were harvested and washed two times with PBS. After pelleting by brief centrifugation at $300 \mathrm{~g}$, the cells were re-suspended in PBS at a density of $1 \times 10^{7}$ cells $/ \mathrm{ml}$. A $200 \mu \mathrm{l}$ aliquote of cell suspension was injected subcutaneously using a tuberculin syringe with a 26 -gauge needle into the dorsal skin of mice under anesthesia $(50 \mathrm{mg} / \mathrm{kg}$ xyladine, and $50 \mathrm{mg} /$ $\mathrm{kg}$ ketamine, intraperitoneally). The day of inoculation was defined as day 0 . After the implantation of LLC cells, the size of the developing tumors was measured with a caliper every 7 days. The tumor volume was calculated according to the formula $\left(V=\left[L \times W^{2}\right] \times 0.5\right)$, where $V=$ volume, $L=$ length, and $W=$ width (length is greater than width). ${ }^{35}$ At 21 days after the injection, mice were killed with an excess dose of chloroform, and tumor tissues were resected, measured, and weighed.

1. angiotensinogen siRNA: the roles of local RAS in tumor growth and tumor-associated angiogenesis were determined by using angiotensinogen siRNA. At 10 days after the injection of LLC cells, WT mice showing tumors were randomly divided into two treatment groups (angiotensinogen siRNA and control siRNA) of five animals each. The siRNA complexed with Atelocollagen was injected directly into the tumor $(2.0 \mu \mathrm{g}$ siRNA/100 $\mu \mathrm{l} /$ tumor) as described by Minakuchi et al. ${ }^{34}$

2. TCV-116: WT and AT1a-/- mice were used in this series. The mice were randomized into the following groups: (a) WT mice treated with vehicle (WT-C) $(n=16)$; (b) WT mice treated with TCV-116 (WT-TCV, $10 \mathrm{mg} / \mathrm{kg} / \mathrm{day}$, orally) $(n=16)$; (c) AT1a-/- mice treated with vehicle (AT-C) $(n=16)$; (d) ATla-l- mice treated with TCV116 (AT-TCV) $(n=17)$. Treatment was started 7 days prior to implantation of LLC cells and following 21-day experimental period.

\section{Western Blot Analysis}

The expression of the AT1 receptor and angiotensinogen protein in LLC cells, and tumor tissues was studied. And VEGFa protein in LLC cells was studied. LLC cells were harvested and lysed in tissue protein extraction reagent (Pierce, Rockford, IL, USA) containing phenylmethylsulfonyl fluoride $(10 \mu \mathrm{g} / \mathrm{ml})$, aprotinin $(10 \mu \mathrm{g} / \mathrm{ml})$, leupeptin $(10 \mu \mathrm{g} /$ $\mathrm{ml}), N$-p-tosyl-L-lysine chloromethyl ketone $(10 \mu \mathrm{g} / \mathrm{ml})$ and 
centrifuged for $10 \mathrm{~min}$ at $3500 \mathrm{~g}$ at $4^{\circ} \mathrm{C}$ to obtain protein extracts. Tumor tissues were removed from the mice 3 weeks after the day of implantation, and homogenized using a Polytron homogenizer (Kinematika AG, Littau, Switzerland) in the protein extraction reagent and centrifuged. After assayed using protein assay reagent (Protein assay, Bio-Rad Laboratories, Hercules, CA, USA), soluble protein was separated on $10 \%$ SDS-polyacrylamide gels and transferred to PVDF membranes (Millipore, Billerica, MA, USA). AT1 receptor antibody (1:1000, Santa Cruz Biotechnology, Santa Cruz, CA, USA), angiotensinogen antibody (1:1000, Santa Cruz Biotechnology), VEGFa antibody (1:1000, Santa Cruz Biotechnology), and $\beta$-actin monoclonal antibody (1:10 000, Sigma) was used to detect AT1 receptor protein, angiotensinogen protein, VEGFa protein, and $\beta$-actin protein, respectively. VSMC cells were used as positive control and HEK 293 cells were used as negative control of AT1 receptor $^{36}$ and angiotensinogen. The immunoreactive bands were visualized by ECL plus reagent (Amersham Biosciences, Piscataway, NJ, USA). The expression of VEGFa protein in LLC cells were analyzed with Scion Image.

\section{Real-Time Quantitative Reverse Transcription-PCR Analysis}

VEGFa, b, c, and d mRNA expression was examined by real-time quantitative reverse transcription (RT)-PCR in LLC cells. Subconfluent cells were pretreated with CV11974 $\left(4 \times 10^{-5} \mathrm{~mol} / \mathrm{l}\right)$ for $6 \mathrm{~h}$, and stimulated with AII $\left(10^{-6}\right.$, $10^{-7} \mathrm{~mol} / \mathrm{l}$ ) for $15 \mathrm{~min}$. In isolated tumor tissues, ATla receptor and AT1b receptor mRNA and other angiogenic factors, such as epidermal growth factor (EGF), epidermal growth factor receptor (EGFR), angiopoietin-1, angiopoietin-2, and vascular endothelial growth factor receptor (VEGFR)-1, and VEGFR-2 mRNA were examined. Total RNA was extracted from cells and tumor tissues using Isogen (Nippon Gene, Tokyo, Japan) according to the manufacturer's instructions and as described Kihara et al. ${ }^{37}$ Total RNA was reverse-transcribed using $25 \mathrm{ng} / \mathrm{ml}$ oligo-(dT) $12-18$ and $10 \mathrm{U} / \mu \mathrm{l}$ Superscript III reverse transcriptase (Invitrogen) with $0.2 \mu \mathrm{g}$ of total RNA per sample. PCR was performed by incubating the RT product with the TaqMan Universal PCR Master Mix and designed TaqMan probe (Applied Biosystems, Foster City, CA, USA). Each experiment was carried out in triplicate. Wells were sealed with optical sheet, and the PCR reaction was run on an ABI prism 7700 using standard conditions. RNA quantity was expressed relative to an $18 \mathrm{~S}$ endogenous control. Relative expression levels were expressed by a comparative threshold cycle $\left(C_{\mathrm{T}}\right)$ method as described previously. ${ }^{32}$

\section{Cell Growth Assay}

Cells $\left(2.5 \times 10^{4}\right.$ cells/well $)$ were plated on 96 -well plates in DMEM with $10 \%$ FBS. After a 24 -h incubation with $10 \%$ FBS, the cells were serum starved for $24 \mathrm{~h}$, and then pretreated with CV11974 $\left(4 \times 10^{-5} \mathrm{~mol} / \mathrm{l}\right)$ for $24 \mathrm{~h}$ and treated with various concentrations of AII $\left(10^{-6}, 10^{-8}, 10^{-10}\right.$, and $10^{-12} \mathrm{~mol} / \mathrm{l}$ ) for $24 \mathrm{~h}$. After a 2 -day treatment, the net number of viable cells was determined using a water-soluble tetrazolium (WST-8) [2-(2-methoxy-4-nitrophenyl)-3-(4nitrophenyl)-5-(2, 4-disulfophenyl)-2H-tetrazolium, monosodium salt] (TetraColor One, Seikagaku Co., Tokyo, Japan) colorimetric assay. Cell growth rate was plotted as ratio to untreated control absorbance.

\section{Enzyme-Linked Immunosorbent Assay and Radioimmunoassay}

Tumor tissues were removed from the mice, and tissues were homogenized in tissue protein extraction reagent (Pierce) and centrifuged. The supernatant was then recovered and the VEGFa levels were determined using a mouse VEGFa enzyme-linked immunosorbent assay (ELISA) kit (R\&D Systems, Minneapolis, MN, USA). The samples were measured in duplicate and averaged. VEGFa levels were expressed relative VEGFa to the VEGFa level of WT-C.

VEGFa levels were also measured in the supernatants of the LLC cells. Briefly, LLC cells at subconfluence were treated with or without AII $\left(10^{-6} \mathrm{~mol} / \mathrm{l}\right)$ and with or without CV11974 $\left(4 \times 10^{-5} \mathrm{~mol} / \mathrm{l}\right)$ for $24 \mathrm{~h}$. The culture media were collected and VEGFa levels were determined.

AII levels were also measured in the supernatants of the LLC cells. After 24-h incubation with 10\% FBS, LLC cells were serum starved for $24 \mathrm{~h}$. The culture media were collected, and AII levels were measured using radioimmunoassay, and the assay was carried out at the laboratory of SRL Inc. (Tokyo, Japan).

\section{Histological and Immunohistochemical Examination}

Tumor tissues were excised from the mice, fixed in IHC zinc fixative (BD Biosciences, San Jose, CA, USA) overnight, and embedded in paraffin. Multiple $3 \mu \mathrm{m}$ tissue slices were prepared from tumors taken from both WT and AT1a- $-1-$ mice ( $n=16-17)$. The dehydrated sections were stained using the labeled streptavidin-biotin complex technique. In brief, the procedure consisted of: (1) incubation with diluted normal goat serum; (2) incubation with rabbit anti-human von Willebrand factor (vWF) antibody (1:200, DAKO A/S, Glostrup, Denmark) to identify microvessels; (3) incubation with biotinylated anti-rabbit IgG and with avidin-biotin peroxidase complex; staining using a commercially available kit (MAX-PO; Nichirei Biosciences Inc., Tokyo, Japan). Final color products were developed using a solution containing 3 , 3 -diaminobenzidine $(\mathrm{DAB})$ and $\mathrm{NiCl}_{2}$ (DAB substrate kit; Nichirei Biosciences Inc). ${ }^{38,39}$

\section{Quantitation of Microvessels}

Microvessel density in the most intensive neovascularization areas (hot spots) was assessed as a parameter of tumor-associated angiogenesis according to the established methods described previously. ${ }^{25,40}$ Briefly, the areas of highest neovascularization were found by scanning the tumors at low 
a
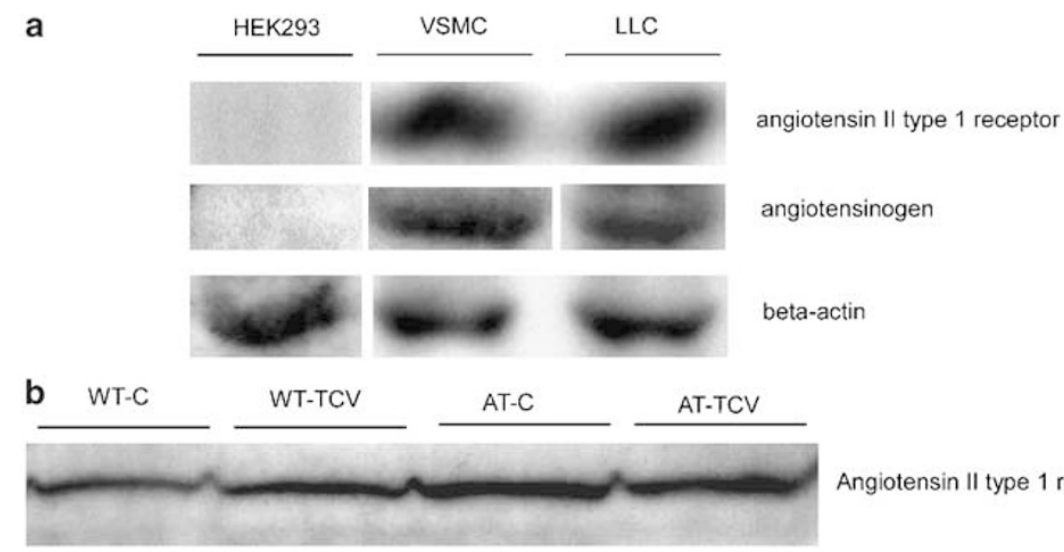

Angiotensin II type 1 receptor

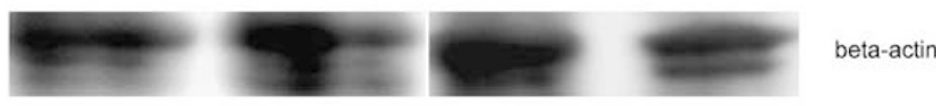

C

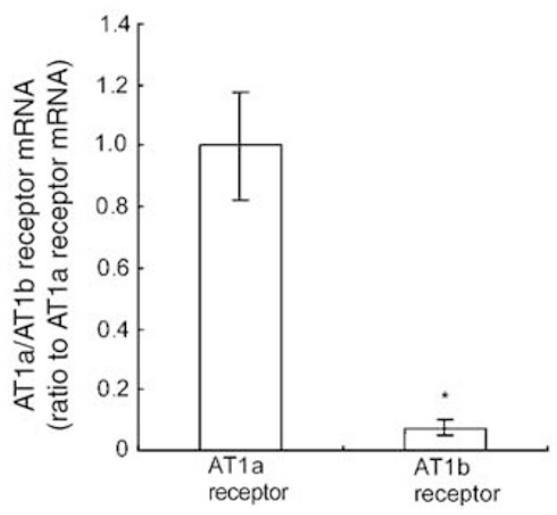

Figure 1 Expression of AT1 receptor and angiotensinogen in Lewis lung carcinoma (LLC) cells in vitro and in vivo. (a) Expression of AT1 receptor and angiotensinogen in cultured LLC cells. HEK293: human embryonic kidney 293 cells were used as negative control and VSMC: vascular smooth muscle cells were used as positive control of AT1 receptor and angiotensinogen. (b) Expression of AT1 receptor in tumor and surrounding stromal tissues in LLC cells-bearing mice. Tumor and stromal tissues were isolated 21 days after tumor implantation. WT-C: WT mice treated with vehicle, WT-TCV: WT mice treated with AT1 receptor antagonist, TCV-116, AT-C: AT1a receptor gene-deficient mouse (AT1a-/-) treated with vehicle, AT-TCV: AT1a-/- mice treated with TCV-116. (c) Expression of AT1b/AT1a receptor mRNA in tumor and surrounding stromal tissues. ${ }^{*} P<0.01$ vs AT1a receptor mRNA (ANOVA). power ( $\times 100$ magnification). After the most vascularized area was identified, the individual microvessels were then counted in three different fields of an area magnified at $\times 200$ in each tissue. The final capillary-density score represents an average of all fields.

\section{Statistics}

All values are presented as mean \pm s.e. ANOVA was used to evaluate the significance of differences with a post hoc test. $P$-values $<0.05$ were considered to be statistically significant.

\section{RESULTS}

\section{All Secretion and AT1 Receptor and Angiotensinogen} Expression in LLC Cells In Vitro and in Allografts In Vivo To clarify the mechanism of AII-induced tumor-associated angiogenesis, we investigated that whether LLC cells secreted AII and expressed AT1 receptor and angiotensinogen. In the supernatants of LLC cells, AII concentration was $7-9 \mathrm{pg} / \mathrm{ml}$, which indicated that LLC cells secreted AII. Western blot analysis had demonstrated that LLC cells as well as VSMC but not HEK 293 cells expressed the AT1 receptor and angiotensinogen in vitro (Figure 1a). LLC allografts grown in WT or AT1a-/- mice in vivo also expressed the AT1 receptor (Figure 1b).

\section{Expression of AT1a and AT1b Receptor in Tumor Tissues}

AT1a receptor mRNA was detectable in LLC allografts in AT1a-I- mice, although the level was significantly lower in AT1a-I- mice than in WT mice. AT1b receptor mRNA was also detected in tumor tissue in AT1a-/- mice, but the level was significantly lower than that of ATla receptor mRNA $(P<0.01)$ (Figure 1c). In contrast to ATla receptor, AT1b receptor mRNA expression was higher in AT1a-l- mice than in WT mice. In both WT and ATla-/- mice, the treatment of TCV-116 enhanced the expression of AT1b receptor mRNA (data not shown).

\section{Effects of CV11974 and All on Cell Growth of Cultured LLC Cells}

The effect of AII on cell growth was tested along with CV11974. As shown in Figure 2a, AII treatment at various doses slightly inhibited the number of LLC cells. The treatment of CV11974 alone showed tendency to increase in the number of LLC cells, but the difference did not reach statistical significance. Therefore, the proliferation of LLC cells was not stimulated directly in vitro by neither exogenously applied AII nor LLC cells-secreted AII. 
Inhibition of Tumor Growth by Angiotensinogen siRNA

Tumor volume was significantly inhibited by treatment with mouse angiotensinogen siRNA in WT mice $(P<0.05)$ (Figure 3a). Western blot analysis revealed that the expression of angiotensinogen was significantly reduced in tumor tissues by locally applied angiotensinogen siRNA (Figure $3 b$ ).

a

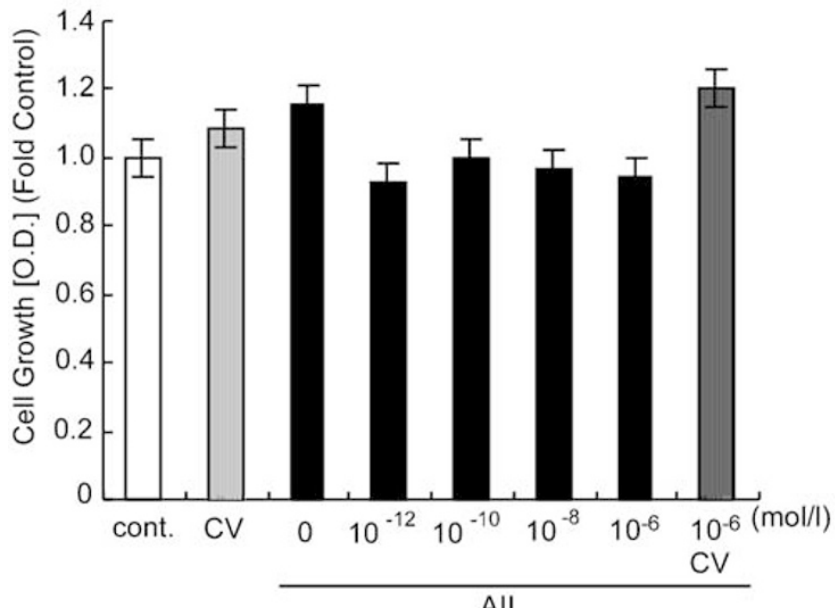

c

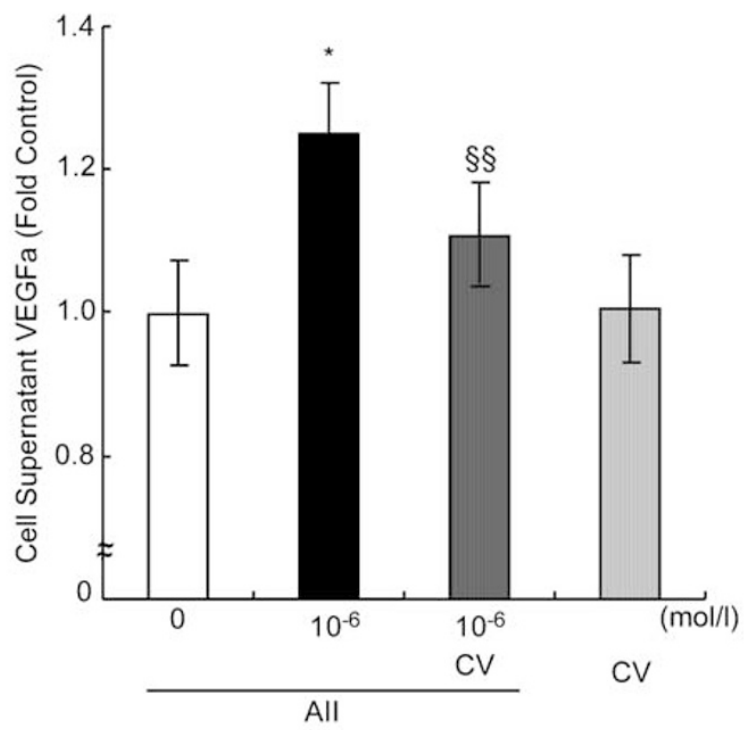

\section{Tumor Growth in WT and AT1a-I- Mice}

LLC cells were implanted into the dorsal skin of WT and ATla-/- mice. Tumor weights of 21 days after tumor implantation were shown in Figure 4a. The mean weight of tumors $(1259.2 \pm 99.7 \mathrm{mg})$ showed a tendency to be lower in AT1a-/- mice compared with those in WT-C $(1551.0 \pm 115.3 \mathrm{mg})$, but the difference did not reach statis-

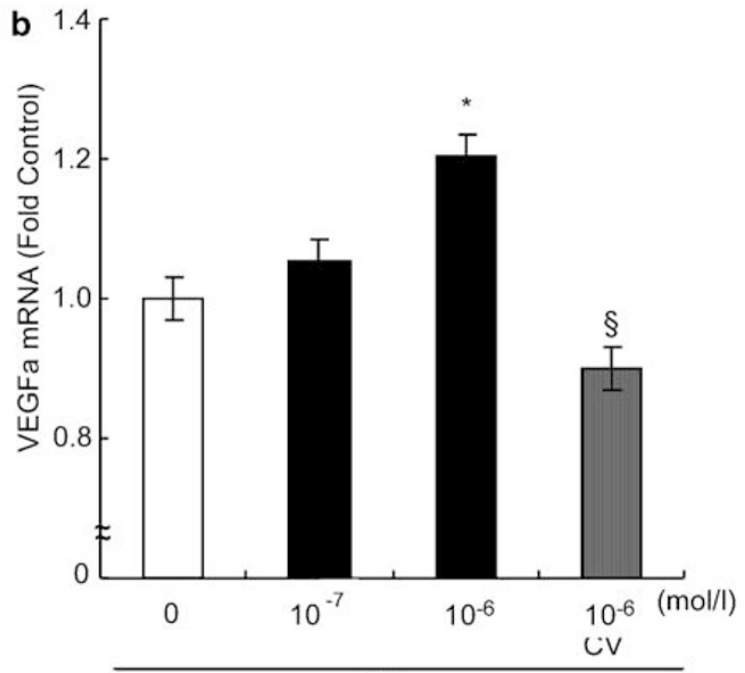

All

d
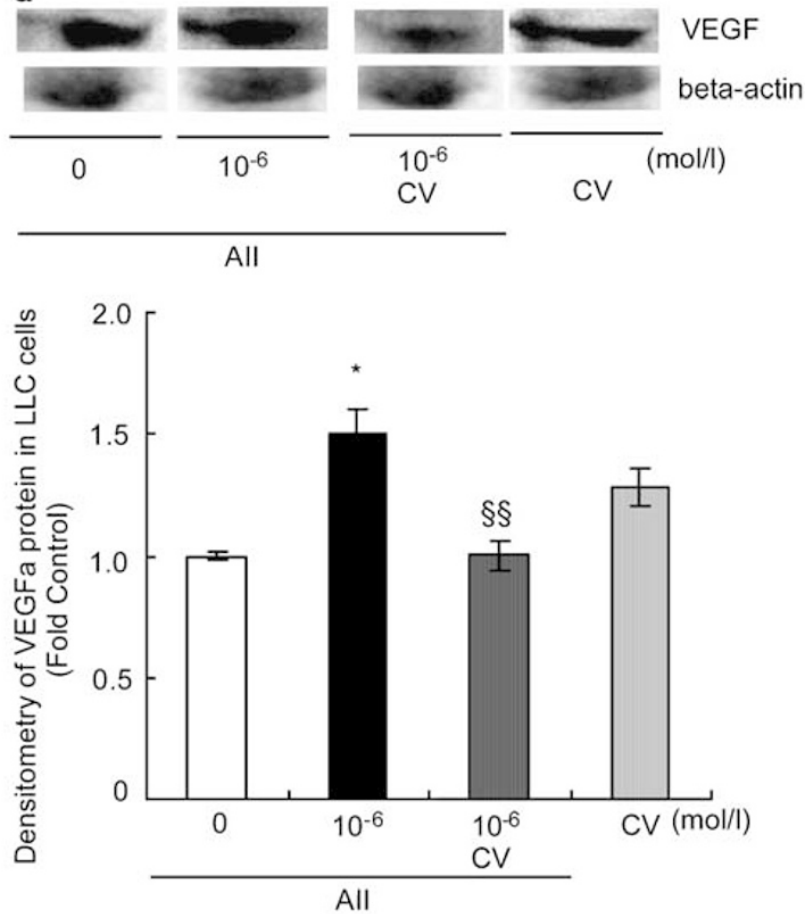

Figure 2 Effects of angiotensin II (All) and AT1 receptor antagonist, CV11974, on proliferation and production of VEGFa in cultured LLC cells. (a) Effects of All and CV11974 (CV) $4 \times 10^{-5} \mathrm{~mol} / \mathrm{I}$ on proliferation of cultured LLC cells evaluated by WST-8 incorporation assay. Cell growth rate was defined as ratio to control absorbance. (b, c) Effects of All on production of VEGFa mRNA (b), and VEGFa protein (c) in cultured LLC cells. (d) Expression of VEGFa protein in cultured LLC cells with All treatment. Black bars show All treatment and bars with vertical stripes show CV-11974 treatment. Values are fold control and mean \pm s.e.m. from 3 experiments in each group. ${ }^{\star} P<0.01$ vs control, ${ }^{\S} P<0.01$ vs All, ${ }^{\S} P<0.05$ vs All (ANOVA). 


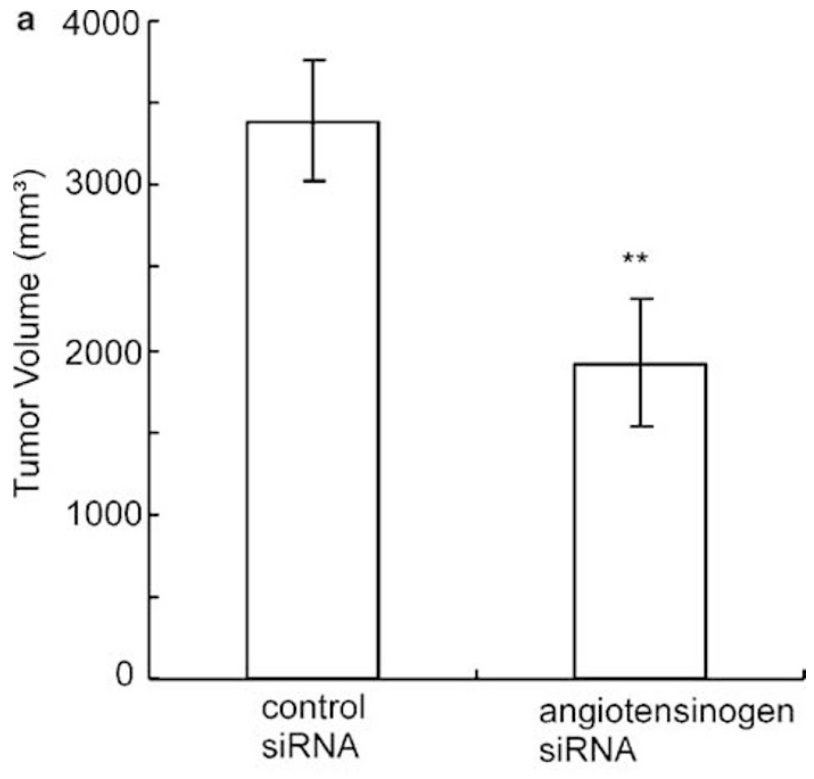

b angiotensinogen

beta-actin

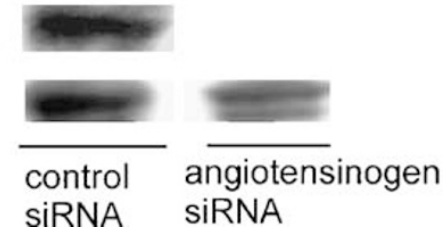

Figure 3 Inhibition of tumor growth by angiotensinogen siRNA. (a) Tumor growth was evaluated by tumor volume 21 days after injection of LLC cell suspension into the subcutaneous tissue of WT mice. At 10 days after the injection of LLC cells, angiotensinogen siRNA $(n=5)$ or control siRNA $(n=5)$ were injected directly into the tumor $(2.0 \mu \mathrm{g}$ siRNA/100 $\mu \mathrm{l} /$ tumor $)$. Data are means \pm s.e.m. ${ }^{* *} P<0.05$ vs control (ANOVA). (b) Expression of angiotensinogen protein in tumor and surrounding stromal tissues in control siRNA and angiotensinogen siRNA groups.

tical significance. WT-TCV $(987.4 \pm 78.2 \mathrm{mg})$ and AT-TCV $(969.4 \pm 91.1 \mathrm{mg})$ mice were significantly smaller than that in WT-C $(P<0.01)$. TCV-116 significantly reduced the weight of tumors in both WT and AT1a-/- mice. In comparing ATla-/- mice with or without TCV-116 treatment, the mean weight of tumors in AT-TCV was significantly smaller than those in AT-C $(P<0.05)$. Together with these data, it was determined that not only the host RAS but also the tumor RAS had important roles in tumor growth.

\section{Microvessel Density}

Microvessel density was evaluated by immunohistochemistry (Figure 4b). The densities of vWF-positive microvessels inside tumors were significantly lower in ATla $-/-$ mice $(8.8 \pm 1.01 \mathrm{vessels} /$ fields, $n=16)$ than in WT mice $(17.3 \pm 1.8$ vessels/fields, $n=16)(P<0.01)$. TCV significantly reduced microvessel density in WT mice and AT1a- $/-$ mice $(P<0.01)$. Also, the microvessel densities in AT-TCV were significantly lower than in AT-C $(P<0.05)$ (Figure $4 c)$. It was noteworthy that in AT1a-/- mice tumor tissues included wider necrotic and bleeding areas than in WT mice.

\section{Effect of All on VEGFa, b, $c$, and d mRNA and VEGFa Protein Production In Vitro}

The expression of VEGFa, b, $c$, and d mRNA and the production of VEGFa protein were studied in LLC cells. Realtime quantitative RT-PCR analysis revealed that $10^{-6} \mathrm{~mol} / \mathrm{l}$ of AII significantly increased the expression of VEGFa mRNA $(P<0.01)$ and that CV 11974 canceled the stimulatory effect of AII $(P<0.01)$ (Figure 2b). A tendency to increase VEGFb, VEGFc, and VEGFd mRNA levels with the treatment of AII was noted, but the differences were not significant (Table 1). VEGFa protein levels in the supernatants of AII treated cells were significantly higher than those in the controls $(P<0.01)$, which were cancelled by CV11974 treatment $(P<0.05)$ (Figure 2c). In Western blot analysis, similar tendency was observed (Figure 2d).

Expression of VEGFa in Tumor-Associated Angiogenesis VEGFa levels in tumor tissues were determined by specific ELISA (Figure 4d). The levels of VEGFa in ATla-/mice were significantly lower than in the WT mice $(P<0.01)$. TCV-116 significantly decreased the levels of VEGFa in both WT and AT1a- - mice $(P<0.01)$. ELISA revealed that VEGFa levels in the tumor tissue with stroma in AT-TCV were significantly lower than those in AT-C $(P<0.01)$.

\section{Expression of Angiopoietin-1, Angiopoietin-2, EGF, EGFR, VEGFR-1, and VEGFR2 in Tumor-Associated Angiogenesis}

Recently, some reports have shown that AII upregulates angiopoietin-2, EGF, and EGFR. ${ }^{18,27}$ So, the expression of other angiogenic factors was investigated. The result was shown in Table 2. The expression of Angiopoietin-1 mRNA was significantly lower in AT1a-/- mice than in WT mice. An-

Figure 4 Tumor growth, tumor-associated angiogenesis and VEGF expression in WT and AT1a-/- mice. (a) Tumor weights after 21 days after tumor implantation in WT mice or AT1a-/ - mice treated with or without oral administration of TCV-116. TCV-116 was administered orally at a dose of $10 \mathrm{mg} / \mathrm{kg} /$ day initiated 7 days before tumor implantation and following 21-day experimental period. WT-C: WT mice treated with vehicle, WT-TCV: WT mice treated with TCV-116, AT-C: AT1a-/- mice treated with vehicle, AT-TCV: AT1a-/- mice treated with TCV-116. (b) Immunohistochemical expression of von Willebrand factor in tumor tissues at the end of the 21-day experiment; (i) WT-C, (ii) WT-TCV, (iii) AT-C, (iv) AT-TCV. $\times 100$ in i-iv. (c) The microvessel densities (/fields) of tumor tissues at the end of the 21-day experiment. (d) VEGFa protein level in the tumor. Black bars show AT1a-/- mice, and bars with vertical stripes show mice with TCV-116 treatment. Data are ratio to WT-C. Data are means \pm s.e.m. ${ }^{*} P<0.01$ vs WT-C $(n=10-16),{ }^{{ }^{\circledR}} P<0.01$ vs AT-C $(n=10-17)$, ${ }_{\$} P<0.05$ vs AT-C $(n=10-17)$ (ANOVA). 
a

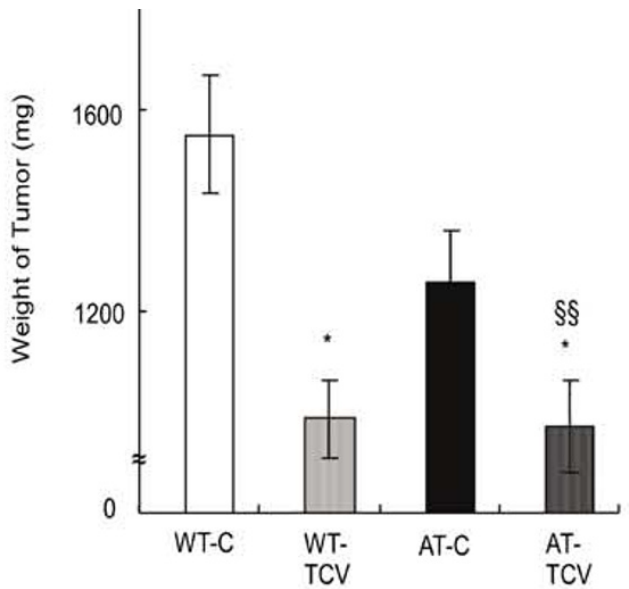

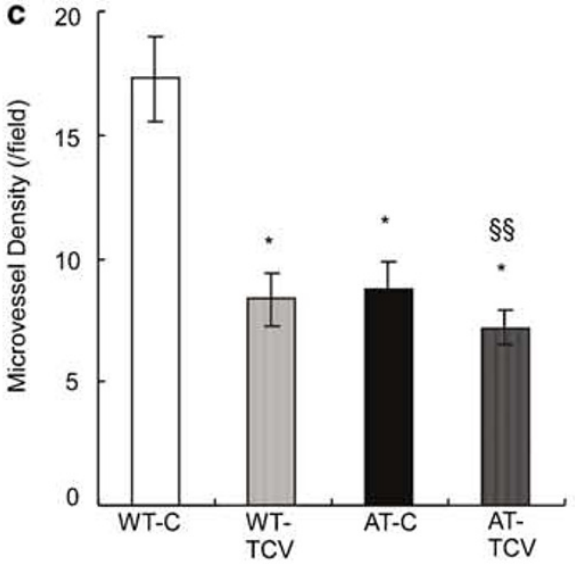

b

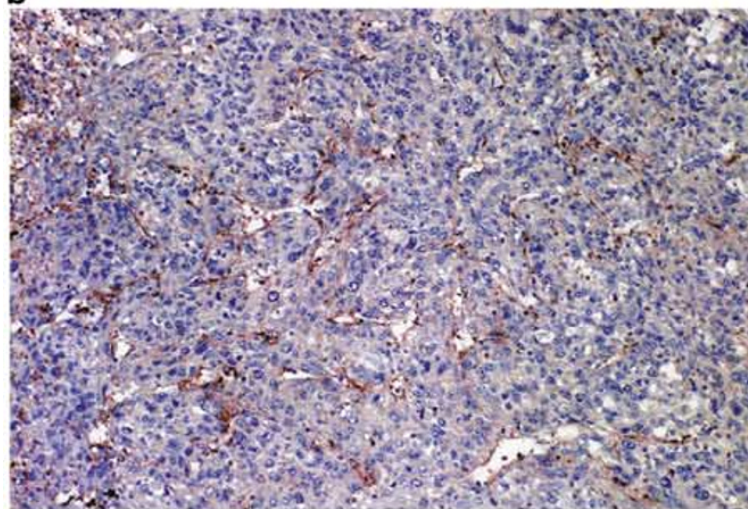

WT-C

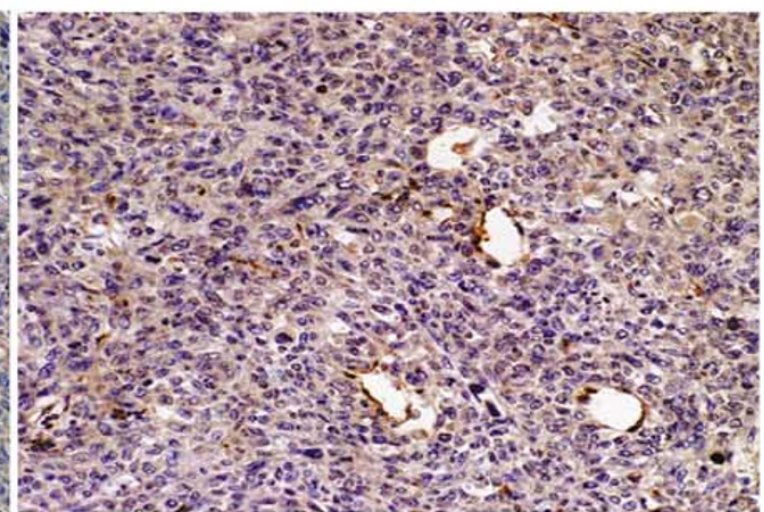

WT-TCV

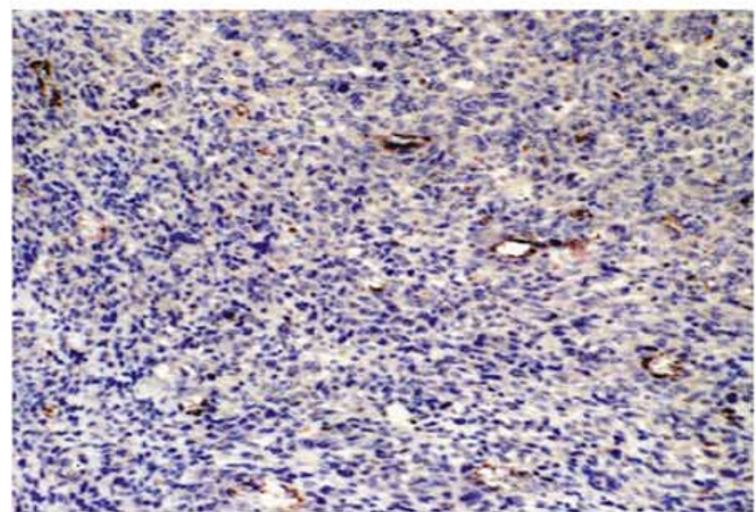

AT-C

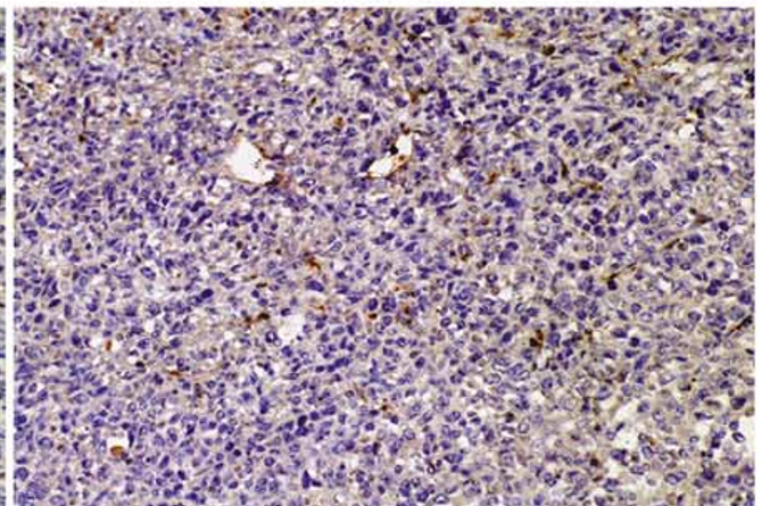

AT-TCV

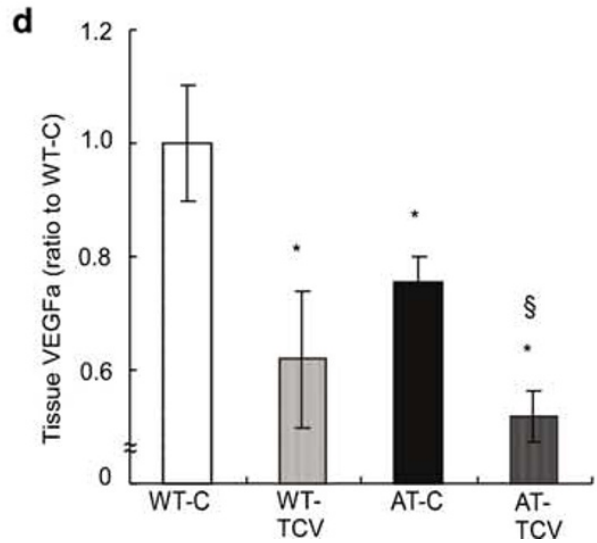


Table 1 Effects of All on production of VEGFb, $c$, and d mRNA in cultured LLC cells

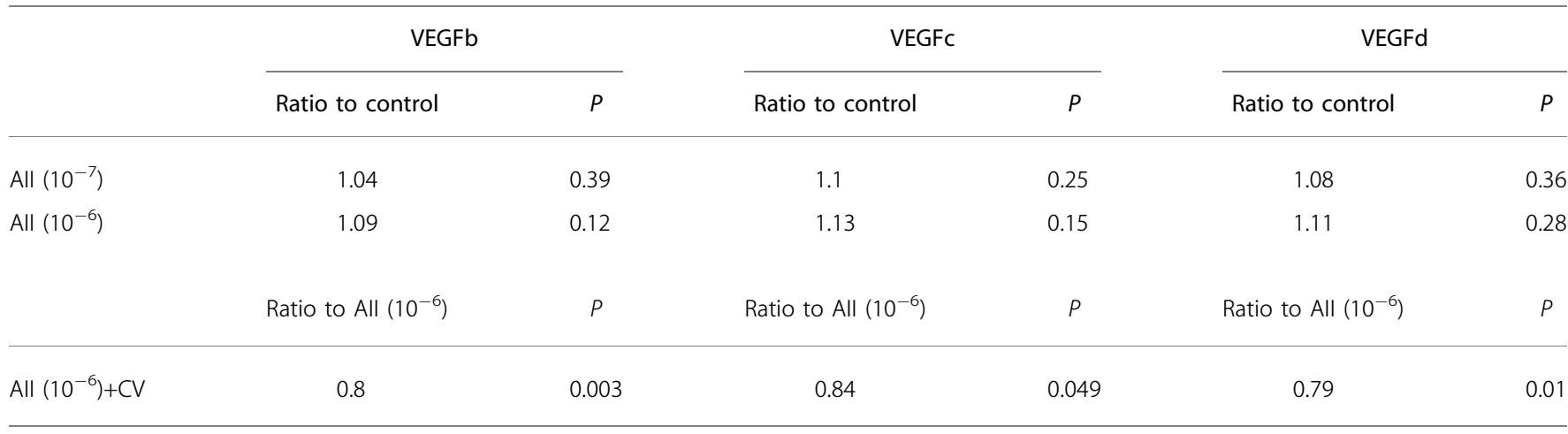

Table 2 Other angiogenic factor mRNA levels in the tumor tissues

\begin{tabular}{|c|c|c|c|c|c|c|}
\hline & Ratio to WT-C & $P$ & Ratio to WT-C & $P$ & Ratio to WT-C & $P$ \\
\hline WT-TCV & 0.68 & 0.02 & 0.8 & 0.02 & 0.8 & 0.08 \\
\hline AT-C & 0.95 & 0.79 & 0.93 & 0.53 & 0.83 & 0.43 \\
\hline & Ratio to AT-C & $P$ & Ratio to AT-C & $P$ & Ratio to AT-C & $P$ \\
\hline AT-TCV & 0.75 & 0.04 & 1.06 & 0.61 & 1.3 & 0.33 \\
\hline WT-TCV & 0.87 & 0.22 & 0.64 & 0.02 & 0.92 & 0.6 \\
\hline AT-C & 0.7 & 0.002 & 0.57 & 0.002 & 0.92 & 0.57 \\
\hline \multirow[t]{2}{*}{ AT-TCV } & 0.79 & 0.03 & 0.73 & 0.13 & 1.13 & 0.4 \\
\hline & Ratio to AT-C & $P$ & Ratio to AT-C & $P$ & Ratio to AT-C & $P$ \\
\hline AT-TCV & 1.14 & 0.21 & 1.28 & 0.14 & 1.23 & 0.21 \\
\hline
\end{tabular}

giopoietin-1 mRNA levels were reduced by TCV-116 in WT mice, but were not affected in AT1a-/- mice. Angiopoietin2 mRNA levels showed no differences between WT and AT1a-/- mice. The expression of EGF mRNAs was reduced in WT-TCV and in AT-TCV in comparison with WT-C. EGF mRNA expressions were similar in WT and AT1a-/- mice. TCV-116 markedly reduced EGF mRNA levels in both WT and AT1a-/- mice. The level of VEGFR2 mRNA was significantly lower in AT1a-/- mice than in WT mice, and was not influenced by TCV-116 treatment. The level of EGFR and VEGFR1 mRNA showed tendency to reduce in WT-TCV compared with WT-C, but showed no significant differences between WT and AT1a-/- mice.

\section{DISCUSSION}

The RAS is an important system in regulating vascular homeostasis, and current evidence is accumulating in support of the idea that AII plays a role in the proliferation, migration, and growth factor synthesis in several types of vascular cells. However, the precise roles of the RAS in angiogenesis, especially in tumor-associated angiogenesis, have not yet been determined. Egami et $a l^{25}$ showed the host 
AII-AT1 receptor pathway played an important role in tumor growth and tumor-associated angiogenesis in vivo by using the ATla-/- mice model in which tumor-associated macrophage infiltration was an important determinant of tumor-associated angiogenesis. Fujita et $a l^{26}$ also showed the host stromal AT1 receptor pathway was important in tumor growth and tumor-associated angiogenesis by using AT1a-/- mice with or without the AT1 antagonist model. Thus, we investigated whether the proangiogenic factors together with activators of RAS could be secreted from tumor cells, and whether these cooperated during tumor-associated angiogenesis, when the AT1 receptor was present in the tumor cells.

AT1a receptor mRNA was detectable in LLC allografts in AT1a-/- mice, thereby suggesting the local synthesis of AT1a receptor in the tumor tissue. AT1b receptor mRNA was also detected in tumor tissue in AT1a-/- mice, although the level was significantly lower than that of AT1a receptor mRNA.

Next, we began by examining whether the block of angiotensinogen in tumor tissue by using mouse angiotensinogen siRNA inhibited tumor growth. In WT mice treated with angiotensinogen siRNA, the tumor size was significantly reduced in comparison with the control group. The local RAS (local AII and local AT1 receptor) in tumor tissues had very important roles in tumor development. The question of which local host or tumor RAS had more important roles in tumor growth was then studied using ATla $-/-$ mice and AT1 receptor antagonist. Allograft models using AT1a-/mice are appropriate to see the contribution of the tumor RAS (AT1a receptor of tumor cells and AII produced by tumor cells), for AT1a-/- mice have no host ATla receptor. Tumor growth and tumor-associated angiogenesis were significantly reduced in AT1a- $/-$ mice. Moreover, tumor growth and tumor-associated angiogenesis were found to be reduced significantly in AT-TCV compared with AT-C. As TCV-116 blocks AT1a and AT1b receptor, next question was whether AT1a receptor in tumor cells or AT1b receptor in host tissues was blocked by TCV-116 when AT1a-/- mice were treated with TCV-116. The AT1b receptor mRNA expression was significantly lower than the AT1a receptor mRNA expression. As the ratio of mRNA for AT1b/AT1a receptors in VSMC cells was $0.59,{ }^{41}$ the expression of AT1b receptor mRNA in our tumor tissue was very low. Although the effect of AT1b receptor of host tissues cannot be ignored, this strongly suggested that the AT1a receptor of tumor cells had more important roles in tumor growth and tumor-associated angiogenesis than AT1b receptor of host tissues. Taken together, the tumor AT1a receptor as well as host ATla receptor had significant roles in tumor growth and tumorassociated angiogenesis.

As many researchers have pointed out, VEGFa is an important mediator of angiogenesis. ${ }^{42}$ The expression of VEGFa protein and production of VEGFa mRNA was increased by stimulation with AII, and reduced significantly by the AT1 receptor antagonist in vitro. Although the change of VEGFa mRNA levels by stimulation with AII was small, but we believe it was biologically significant because the level of VEGFa protein was also increased by AII. In vivo, the level of VEGFa protein was significantly lower in ATla $-/-$ mice than in WT mice. Moreover, the level of VEGFa protein was significantly lower in AT-TCV than in AT-C. Fujita et $a l^{26}$ showed the administration of an AT1 receptor antagonist did not suppress the expression of VEGFa in tumor tissues of AT1a-/mice, which had no detectable AT1 receptor. Our study clearly demonstrated that the AT1 receptor was detected by western blot analysis in the LLC cells. Kang et al ${ }^{43}$ showed that AII stimulated the synthesis of VEGFa in podocytes and that the production of VEGFa induced by AII was mediated, in part, through the activation of the p38 mitogen activated protein kinase pathway. Suganuma et al ${ }^{44}$ also showed that AII enhanced tumor cell invasion and VEGFa secretion via AT1 receptor in ovarian cancer cell lines in vitro. Therefore, the difference of VEGFa production may be caused by the expression of AT1 receptor in tumor cells. Our results suggest that the tumor RAS plays an important role in promoting tumor angiogenesis through the induction of VEGFa in vivo and in vitro. As human pancreas, breast, skin, prostate, brain, cervix, and ovarian carcinoma cells have AT1 receptors, ${ }^{18}$ this concept may have applications to cancer therapy.

In lung cancer cells, our experiments provided the first evidence for AT1 receptor mediated VEGFa, VEGFR2, and angiopoietin-1 levels upregulation. When AT1 receptor was present in the tumor cells, AII may promote tumor-associated angiogenesis via various angiogenic factors. However we think that the most important angiogenic factor is VEGFa via the AT1 receptor, because VEGFa was most correlated with tumor size.

In conclusion, the present study shows that tumor and host VEGFa induction mediated by tumor and host RAS are key regulators of tumor growth and tumor-associated angiogenesis and that a new mechanism for the blockade of AT1 receptor signaling in tumor-associated angiogenesis, which may become an effective novel strategy for the chemoprevention of neoplasms.

\section{ACKNOWLEDGEMENTS}

We thank Hiroko Morinaga and Emi Maeda for technical assistance. This study was supported by grants from the 21 st Century COE Program, the Japan Society for the Promotion of Science (JSPS), a grant-in-aid for Scientific Research from the JSPS $(2004,16590704),(2004,16590892)$, and a grant-in-aid for Young Scientists from the Ministry of Education, Culture, Sports, Science and Technology of Japan (2004, 16790425).

1. Brunner HR, Laragh JH, Baer L, et al. Essential hypertension: renin and aldosterone, heart attack and stroke. N Engl J Med 1972;286:441-449.

2. Kim S, Iwao H. Molecular and cellular mechanisms of angiotensin IImediated cardiovascular and renal diseases. Pharmacol Rev 2000;52:11-34.

3. Timmermans PB, Wong PC, Chiu AT, et al. Angiotensin II receptors and angiotensin II receptor antagonists. Pharmacol Rev 1993;45:205-251.

4. Burnier M. Angiotensin II type 1 receptor blockers. Circulation 2001;103:904-912. 
5. Viswanathan M, Stromberg C, Seltzer A, et al. Balloon angioplasty enhances the expression of angiotensin II AT1 receptors in neointima of rat aorta. J Clin Invest 1992;90:1707-1712.

6. Harada K, Komuro I, Sugaya T, et al. Vascular injury causes neointimal formation in angiotensin II type 1a receptor knockout mice. Circ Res 1999;84:179-185.

7. Rossig L, Dimmeler S, Zeiher AM. Apoptosis in the vascular wall and atheroscrelosis. Basic Res Cardiol 2001;96:11-22.

8. Wesselman JP, De Mey JG. Angiotensin and cytoskeletal proteins: role in vascular remodeling. Curr Hypertens Rep 2002;4:63-70.

9. Inokuchi Y, Morohashi T, Kawana I, et al. Amelioration of 2, 4, 6trinitrobenzene sulphonic acid induced colitis in angiotensinogen gene knockout mice. Gut 2005;54:349-356.

10. Tamarat R, Silvestre JS, Duriez M, et al. Angiotensin II angiogenic effect in vivo involves vascular endothelial growth factor-and inflammationrelated pathways. Lab Invest 2002:82:747-756.

11. Sasaki K, Murohara T, Ikeda $H$, et al. Evidence for the importance of angiotensin II type 1 receptor in ischemia-induced angiogenesis. J Clin Invest 2002;109:603-611.

12. Bell L, Madri JA. Influence of the angiotensin system on endothelial and smooth muscle cell migration. Am J Pathol 1990;137:7-12.

13. Paquet J, Baudouin-Legros M, Carbini L, et al. Angiotensin Il-induced proliferation of aortic myocytes in spontaneously hypertensive rats. J Hypertens 1990;8:565-572.

14. Nadal JA, Scicli GM, Carbini LA, et al. Angiotensin II and retinal pericytes migration. Biochem Biophys Res Commun 1999;266:382-385

15. Otani A, Takagi $\mathrm{H}$, Oh $\mathrm{H}$, et al. Angiotensin Il-stimulated vascular endothelial growth factor expression in bovine retinal pericytes. Invest Ophthalmol Vis Sci 2000;41:1192-1199.

16. Andrade SP, Cardoso CC, Machado RD, et al. Angiotensin-Il-induced angiogenesis in sponge implants in mice. Int J Microcirc Clin Exp 1996;16:302-307.

17. Hu DE, Hiley CR, Fan TP, et al. Comparative studies of the angiogenic activity of vasoactive intestinal peptide, endothelins- 1 and -3 and angiotensin II in a rat sponge model. Br J Pharmacol 1996;117:545-551.

18. Deshayes F, Nahmias C. Angiotensin receptors: a new role in cancer? Trends Endoclinol Metab 2005;16:293-299.

19. Lever AF, Hole DJ, Gillis CR, et al. Do inhibitors of angiotensin-Iconverting enzyme protect against risk of cancer? Lancet 1998;352:179-184.

20. Yoshiji H, Kuriyama S, Kawata $M$, et al. The angiotensin-l-converting enzyme inhibitor Perindopril suppresses tumor growth and angiogenesis: possible role of the vascular endothelial growth factor. Clin Cancer Res 2001;7:1073-1078.

21. Yoshiji H, Yoshii J, Ikenaka $\mathrm{Y}$, et al. Suppression of the reninangiotensin system attenuates vascular endothelial growth factor-mediated tumor development and angiogenesis in murine hepatocellular carcinoma cell. Int J Oncol 2002;20:1227-1231.

22. Yasumatsu R, Nakashima T, Masuda M, et al. Effects of the angiotensinl-converting enzyme inhibitor perindopril on tumor growth and angiogenesis in head and neck squamous cell carcinoma cells. J Cancer Res Clin Oncol 2004;130:567-573.

23. Fabre JE, Rivard A, Magner M, et al. Tissue inhibition of angiotensinconverting enzyme activity stimulates angiogenesis in vivo. Circulation 1999;99:3043-3049.

24. Takeshita S, Tomiyama $\mathrm{H}$, Yokoyama $\mathrm{N}$, et al. Angiotensin-converting enzyme inhibition improves defective angiogenesis in the ischemic limb of spontaneously hypertensive rats. Cardiovasc Res 2001;52: 314-320.

25. Egami K, Murohara T, Shimada T, et al. Role of host angiotensin II type 1 receptor in tumor angiogenesis and growth. J Clin Invest 2003;112:67-75

26. Fujita M, Hayashi I, Yamashina $S$, et al. Angiotensin type 1a receptor signaling-dependent induction of vascular endothelial growth factor in stroma is relevant to tumor-associated angiogenesis and tumor growth. Carcinogenesis 2005;26:271-279.

27. Uemura $H$, Ishiguro $H$, Nagashima $Y$, et al. Antiproliferative activity of angiotensin II receptor blocker through cross-talk between stromal and epithelial prostate cancer cells. Mol Cancer Ther 2005;4:1699-1709.

28. Miyajima A, Kosaka T, Asano T, et al. Angiotensin II type I antagonist prevents pulmonary metastasis of murine renal cancer by inhibiting tumor angiogenesis. Cancer Res 2002;62:4176-4179.

29. Fujimoto $Y$, Sasaki T, Tsuchida A, et al. Angiotensin II type 1 receptor expression in human pancreatic cancer and growth inhibition by angiotensin II type 1 receptor antagonist. FEBS Lett 2001;495:197-200.

30. Shibouta $Y$, Inada $Y$, Ojima M, et al. Pharmacological profile of a highly potent and long-acting angiotensin II receptor antagonist, 2-ethoxy$1-\left\{\left[2^{\prime}-(1 \mathrm{H}\right.\right.$-tetrazol-5-yl) biphenyl-4-yl $]$ methyl $\}-1 \mathrm{H}$ benzimidazole7-carboxylic acid (CV11974), and its prodrug, (+/-)-1(cyclohexyloxycarbonyloxy)-ethyl 2-ethoxy-1-\{[2'-(1H-tetrazol-5-yl) biphenyl-4-yl] methyl\}-1H-benzimidazole-7-carboxylate (TCV-116). J Pharmacol Exp Ther 1993;266:114-120.

31. Bertram JS, Janik P. Establishment of a cloned line of lewis lung carcinoma cells adapted to cell culture. Cancer Lett 1980;11:63-73.

32. Hashimoto $T$, Kihara M, Sato $K$, et al. Heparin recovers AT1 receptor and its intracellular signal transduction in cultured vascular smooth muscle cells. FEBS Lett 2005;579:281-284.

33. Sugaya T, Nishimatsu S, Tanimoto K, et al. Angiotensin II type 1a receptor-deficient mice with hypotension and hyperreninemia. J Biol Chem 1995;270:18719-18722.

34. Minakuchi Y, Takeshita F, Kosaka N, et al. Atelocollagen-mediated synthetic small interfering RNA delivery for effective gene silencing in vitro and in vivo. Nucleic Acids Res 2004;32:e109.

35. Ishii $\mathrm{H}$, Yazawa $\mathrm{T}$, Sato $\mathrm{H}$, et al. Enhancement of pleural dissemination and lymph node metastasis of intrathoracic lung cancer cells by vascular endothelial growth factors (VEGFs). Lung Cancer 2004;45 325-337.

36. Ishida J, Asada S, Daitoku $\mathrm{H}$, et al. Expression and characterization of mouse angiotensin II type 1a receptor tagging hemagglutinin epitope in cultured cells. Int J Mol Med 1999:3:263-270.

37. Kihara M, Sato $K$, Hashimoto $T$, et al. Expression of endothelial nitric oxide synthase is suppressed in the renal vasculature of angiotensinogen-gene knockout mice. Cell Tissue Res 2006;323: 313-320.

38. Sato $\mathrm{K}$, Kihara $\mathrm{M}$, Hashimoto $\mathrm{T}$, et al. Alteration in renal endothelial nitric oxide synthase expression by salt diet in angiotensin type-1a receptor gene knockout mice. J Am Soc Nephrol 2004;15:1756-1763.

39. Hashimoto T, Kihara M, Ishida J, et al. Apelin stimulates myosin light chain phosphorylation in vascular smooth muscle cells. Arterioscler Thromb Vasc Biol 2006;26:1267-1272.

40. Ziada AM, Hudlicka O, Tyler KR, et al. The effect of long-term vasodilation on capillary growth and performance in rabbit heart and skeletal muscle. Cardiovasc Res 1984;18:724-732.

41. Zhu Z, Zhang SH, Wagner C, et al. Angiotensin AT1b receptor mediated calcium signaling in vascular smooth muscle cells of AT1a receptor-deficient mice. Hypertension 1998;31:1171-1177.

42. Kim KJ, Li B, Winer J, et al. Inhibition of vascular endothelial growth factor-induced angiogenesis suppresses tumor growth in vivo. Nature 1993;362:841-844.

43. Kang YS, Park YG, Kim BK, et al. Angiotensin II stimulates the synthesis of vascular endothelial growth factor through the p38 mitogen activated protein kinase pathway in cultured mouse podocytes. $\mathrm{J}$ Mol Endocrinol 2006;36:377-388.

44. Suganuma $T$, Ino $K$, Shibata $K$, et al. Functional expression of the angiotensin II type 1 receptor in human ovarian carcinoma cells and its blockade therapy resulting in suppression of tumor invasion, angiogenesis, and peritoneal dissemination. Clin Cancer Res 2005;11:2686-2694. 